\title{
Seroprevalence of HIV-1 infection in a cohort of homosexually active men
}

\author{
A J Hunt, G Christofinis, A P M Coxon, P M Davies, T J McManus, S Sutherland, \\ $P$ Weatherburn
}

\begin{abstract}
A non-clinic cohort of 525 homosexually active men from London and South Wales were recruited in 1988 for a study by interview of sexual behaviour. A sample of blood was tested for HIV-1 antibodies. Seropositivity in London was $9 \cdot 2 \%$ compared with $3 \cdot 4 \%$ in South Wales. Men who were not regular STD clinic attenders had a lower rate of seropositivity than did those who were regular attenders. Men who were seropositive reported more sexual partners with whom they had anal intercourse and also reported more episodes of syphilis. Overall, rates of seropositivity were lower than those reported by studies from STD clinics.
\end{abstract}

\section{Introduction}

Homosexually active men remain the largest single group in the reported prevalence figures for AIDS in the United Kingdom. All the available information about the prevalence of HIV in this group of men is based on studies undertaken on men attending STD clinics, as is the bulk of information on changes in the sexual behaviour in response to HIV.

Project SIGMA was set up in 1987 to study the lifestyles of gay and bisexual men using a non-clinic cohort. The project consists of a set of inter-related studies, the largest of which is a 3 year, three phase two-centre non-clinic cohort study of seroprevalence and sexual behaviour, together with associated psychological and social factors. The data come from interviews and blood samples collected in London

Department of Social Sciences, South Bank Polytechnic, London

A J Hunt, P M Davies, P Weatherburn

Dulwich Hospital Public Health Laboratory Services, London

G Christofinis, S Sutherland

British Household Panel Study, University of Essex, Colchester

A P M Coxon

Department of Genito-Urinary Medicine, King's College Hospital, London

T J McManus and South Wales (strictly, the counties of Glamorgan and Gwent). Its main aims are (1) to estimate the prevalence of HIV antibody in homosexually active men; (2) to assess the uptake and spread of safer sexual practices and (3) to estimate, over a three year period the rate of seroconversion in that group.

In this article we report the results of the first phase of the study relating to the prevalence of HIV antibody found in the cohort, together with factors associated with positivity.

\section{Subjects and methods}

A pool of 778 (London, 508, South Wales, 270) gay and bisexual men were recruited from advertisements in the gay press, gay clubs and pubs, talks to social groups etc and through the strategy of snowballing (that is, sampling through the social networks of respondents). A total of $310(61 \%)$ in London and $215(79 \%)$ in South Wales responded to the invitation to be interviewed.

Men who enrolled in the study were asked (but not required) to provide a sample of blood for the HIV antibody test. Samples were taken by trained interviewers following counselling about the test and its implications. They were given the further option of receiving the result, in which case, further counselling was provided by trained counsellers.

Information on demographic variables, sexual practices, health, knowledge about AIDS, HIV and safer sex and measures of psychological well-being was collected by means of a structured interview, lasting on average three hours but on an occasion taking up to five.

Data were put on computer and statistical analyses performed. Where distributions were highly skewed, suitable transformations of the data were made before ANOVA and other tests with assumptions about data distributions were carried out. Chi-square tests were carried out with Yates' correction where appropriate.

Sera were screened initially by a competitive enzyme immunoassay (ELISA) for HIV antibody (Wellcozyme, Wellcome) and positively reacting sera were confirmed by an indirect ELISA (Anti-HIV, 2nd generation, Abbott). Further confirmatory tests were carried out at an HIV reference laboratory using competitive and IgG capture in-house assays for HIV antibody. 
Table 1 Demographic characteristics of cohort

\begin{tabular}{lll}
\hline & London & South Wales \\
\hline Age $(y r)$ & & \\
mean & 33 & 35 \\
median & 30 & 28 \\
range & $16-81$ & $17-76$ \\
Marital status & & \\
single & & \\
married & $275(88 \%)$ & $187(87 \%)$ \\
sep/div/wid & $11(4 \%)$ & $11(5 \%)$ \\
& $24(8 \%)$ & $17(8 \%)$ \\
Gay relationship status & & \\
1 regular & $70(23 \%)$ & $56(26 \%)$ \\
$\geqslant 1$ reg \& others & $104(33 \%)$ & $69(32 \%)$ \\
no regular & $135(44 \%)$ & $90(42 \%)$ \\
\hline
\end{tabular}

\section{Results}

The demographic characteristics of the two cohorts are shown in table 1. Data were obtained from 525 men, 310 in London and 215 in South Wales. The median age in the cohorts was 30 years in London, 28 in South Wales, with ranges from 16 to 81 and 17 to 76 respectively. The distributions are highly skewed. In London 291 (93\%) and in South Wales $175(81 \%)$ classed themselves as being "exclusively homosexual" or "predominantly homosexual with a slight degree of heterosexuality" in terms of their sexual feelings. However, $11(4 \%)$ men in London and 11 $(5 \%)$ in South Wales were currently married and a further $24(8 \%)$ in London and $17(8 \%)$ in South Wales had previously been married but were now divorced, separated or widowed.

In the capital, $70(23 \%)$ and in the provinces 56 $(26 \%)$ were currently involved in a regular sexual relationship with another man, to whom he was sexually exclusive. A further $104(33 \%)$ in London and $69(32 \%)$ in South Wales were either involved in a sexual relationship and had other casual partners, or were involved in more than one regular relationship. The remaining $135(44 \%)$ in London and 90

Table 2 Characteristics of those taking and not taking HIV antibody test

\begin{tabular}{|c|c|c|c|}
\hline & $\begin{array}{l}\text { Age (yr) } \\
\text { (Median)* }\end{array}$ & $\begin{array}{l}\text { Clinic } \\
\text { attenders } \\
(N, \%)\end{array}$ & $\begin{array}{l}\text { Previous } \\
\text { test } \\
(N, \%)\end{array}$ \\
\hline $\begin{array}{l}\text { London } \\
\text { Total }(N=310) \\
\text { Tested }(N=206) \\
\text { Not tested }(N=104) \\
\text { Significance }(p=)\end{array}$ & $\begin{array}{l}30 \\
29 \\
31 \\
0.026\end{array}$ & $\begin{array}{c}126(40 \cdot 6) \\
90(43 \cdot 7) \\
36(34 \cdot 6) \\
0 \cdot 19\end{array}$ & $\begin{array}{c}137(44 \cdot 2) \\
94(45 \cdot 6) \\
43(41 \cdot 3) \\
0 \cdot 22\end{array}$ \\
\hline $\begin{array}{l}\text { South Wales } \\
\text { Total }(N=215) \\
\text { Tested }(N=147) \\
\text { Not tested }(N=68) \\
\text { Significance }(p=)\end{array}$ & $\begin{array}{l}31 \\
30 \\
32 \\
0 \cdot 14\end{array}$ & $\begin{array}{l}36(16 \cdot 7) \\
21(14 \cdot 3) \\
15(22 \cdot 1) \\
0.57\end{array}$ & $\begin{array}{c}76(35 \cdot 3) \\
50(34 \cdot 0) \\
26(38 \cdot 2) \\
0.68\end{array}$ \\
\hline
\end{tabular}

*Tests of significance carried out on means with suitable transformations.
Table 3 Rates of seroprevalence in the cohorts

\begin{tabular}{lcc}
\hline & London & South Wales \\
\hline $\begin{array}{l}\text { Bloods tested in study only } \\
\text { Positive }\end{array}$ & $19 / 206(9 \cdot 2)$ & $5 / 147(3 \cdot 4)$ \\
$\quad$ Negative & $187 / 206(90 \cdot 8)$ & $142 / 147(96 \cdot 6)$ \\
& & \\
$\begin{array}{l}\text { Including previous results } \\
\text { Positive }\end{array}$ & $31 / 225(13 \cdot 8)$ & $7 / 159(4 \cdot 4)$ \\
Negative & $194 / 225(86 \cdot 2)$ & $152 / 159(95 \cdot 6)$ \\
\hline
\end{tabular}

'See main text for inclusion criteria.

$(42 \%)$ in South Wales had no regular relationship at the time of interview. This includes men who had only casual sexual partners in the month before interview and a small number ( 33 men) who were currently celibate.

Reported prevalence of intravenous drug use was negligible $(<1 \%)$.

Only $30.9 \%$ of those interviewed claimed to be regular attenders at genitourinary medicine clinics and had attended at least once in the year before interview. In London, 129 (44\%) previously knew their HIV antibody status.

In London, 206/310 (66\%) and in South Wales $(147 / 215)(68 \%)$ of the sample agreed to give blood. The characteristics of the two groups are shown in table 2. Although those giving blood were significantly younger $\left(\mu_{\text {(testing) }}=32.9, \mu_{\text {(not testing) }}=35.6\right.$, $\left.\left.\mu_{\text {(overall) }}=33.9, \mathrm{~F}=5.04, \mathrm{df}=1,309\right), \mathrm{p}<0.05\right)$ than those who do not, there is no significant difference at the $5 \%$ level between the groups in terms of their (gay) relationship status, highest education qualification, social class, the degree to which they were open about their gay identity, or their degree of homosexual feelings (Kinsey rating).

Most importantly, there was no significant relationship between clinic attendance and the decision to give blood in this study. Nor were those who had previously taken the HIV antibody test more likely to give blood. We therefore have some confidence that this study is reporting reşults from

Table 4 Characteristics of those testing negative and those testing positive to HIV antibody

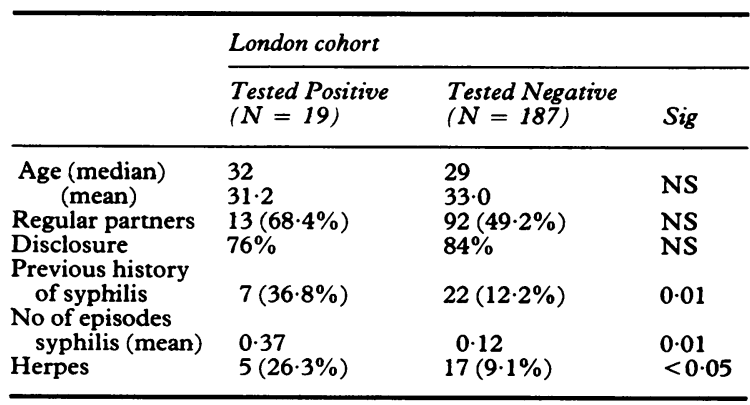


Table 5 Numbers of partners and PSPS of sero-negatives and seropositives

\begin{tabular}{|c|c|c|c|c|c|c|c|c|}
\hline & \multicolumn{4}{|c|}{ Negatives } & \multicolumn{4}{|c|}{ Positives } \\
\hline & Mean & (Median) & $\begin{array}{l}\text { Lower } \\
\text { Qu'ile }\end{array}$ & $\begin{array}{l}\text { Upper } \\
Q u^{\prime} \text { ile }\end{array}$ & Mean & (Median) & $\begin{array}{l}\text { Lower } \\
\text { Qu'ile }\end{array}$ & $\begin{array}{l}\text { Upper } \\
\text { Qu'ile }\end{array}$ \\
\hline $\begin{array}{l}\text { Whole Life } \\
\text { Partiners } \\
\text { PSPS }\end{array}$ & $\begin{array}{r}452 \cdot 7 \\
99 \cdot 4\end{array}$ & $\begin{array}{l}(50) \\
(10)\end{array}$ & $\begin{array}{r}15 \\
2\end{array}$ & $\begin{array}{r}250 \\
30\end{array}$ & $\begin{array}{l}528 \cdot 7 \\
198 \cdot 0\end{array}$ & $\begin{array}{r}(200) \\
(50)\end{array}$ & $\begin{array}{r}40 \\
6\end{array}$ & $\begin{array}{l}800 \\
480\end{array}$ \\
\hline $\begin{array}{l}\text { Last } 5 \text { years } \\
\text { Partners } \\
\text { PSPS }\end{array}$ & $\begin{array}{l}64 \cdot 2 \\
10 \cdot 2\end{array}$ & $\begin{array}{r}(20) \\
(3)\end{array}$ & $\begin{array}{l}7 \\
1\end{array}$ & $\begin{array}{r}50 \\
9\end{array}$ & $\begin{array}{r}144 \cdot 4 \\
46 \cdot 3\end{array}$ & $\begin{array}{l}(40) \\
(17)\end{array}$ & $\begin{array}{r}17 \\
4\end{array}$ & $\begin{array}{r}150 \\
40\end{array}$ \\
\hline $\begin{array}{l}\text { Last year } \\
\text { Partners } \\
\text { PSPS }\end{array}$ & $\begin{array}{r}13.8 \\
2.5\end{array}$ & $\begin{array}{l}(6) \\
(1)\end{array}$ & $\begin{array}{l}2 \\
0\end{array}$ & $\begin{array}{r}14 \\
2\end{array}$ & $\begin{array}{r}24.6 \\
5.9\end{array}$ & $\begin{array}{l}(6) \\
(1)\end{array}$ & $\begin{array}{l}3 \\
0\end{array}$ & $\begin{array}{r}22 \\
7\end{array}$ \\
\hline $\begin{array}{l}\text { Last month } \\
\text { Partners } \\
\text { PSPS }\end{array}$ & $\begin{array}{l}2.1 \\
0.5\end{array}$ & $\begin{array}{l}(1) \\
(0)\end{array}$ & $\begin{array}{l}1 \\
0\end{array}$ & $\begin{array}{l}3 \\
1\end{array}$ & $\begin{array}{l}3 \cdot 1 \\
1 \cdot 0\end{array}$ & $\begin{array}{l}(1) \\
(0)\end{array}$ & $\begin{array}{l}0 \\
0\end{array}$ & $\begin{array}{l}4 \\
1\end{array}$ \\
\hline
\end{tabular}

gay and bisexual men who do not appear in clinicbased research samples.

Of the 206 bloods tested from London, $19(9 \cdot 2 \%)$ and of the 147 from South Wales, $5(3.4 \%)$ were positive for HIV-1 antibody (see table 3). Some difficulties arise when we consider those men who have a previous test result but who did not volunteer blood in this study. While it seems reasonable to include those who knew themselves to be antibody positive prior to the research, it is not so clear what to do with those who have a negative test result, in the sense that a negative result from a test taken three weeks ago has a different current validity from one taken three years previously. If, therefore, those who had a negative test result during the period of the research (October 1987-July 1988) are included, rates of $31 / 225(13.8 \%)$ in London and $7 / 159(4.4 \%)$ in South Wales are obtained.

Using the results from the tested bloods only, the rate of seropositivity among clinic attenders is higher than that among non-attenders. In our London cohort, the proportion of clinic attenders which is positive is over $15.6 \%$, within the range reported by the clinic studies, while among non-attenders, the figure is $3.8 \%\left(\chi^{2}=11.35, \mathrm{df}=1, \mathrm{p}=0.0018\right.$ with Yates' correction). Similarly, the proportion of seropositives among that group which has taken the antibody test previously is $13.8 \%$, and among those who have not done so, the rate is $5.8 \%\left(\mathrm{X}_{\text {(Yates) }}^{2}\right.$ $=2.97, \mathrm{p}=0.08$ ).

Since the number of men testing positive in South Wales is so small, attempts to discern characteristics would be hazardous and subsequent analyses refer to the London cohort (see table 4). There is no statistically significant difference between the seropositives and the sero-negatives on demographic variables, although a number of clear trends emerge. The positives tend to be younger than negatives, $(\mu(+\mathrm{ve})=31, \mu(-\mathrm{ve})=33, \mathrm{~F}=0.075, \mathrm{df}=1$, $198, \mathrm{p}=0.78)$. It is disturbing to note a slightly higher HIV-1 seroprevalence rate among the 111 respondents under 21 years of age (that is, $5 / 32$ or $15.6 \%$ were antibody positive) although this is not significantly higher than older age groups $\left(\mathrm{X}_{\left(\text {Yates }^{2}\right.}^{2}=1 \cdot 04, \mathrm{p}=0.36\right)$.

Those who tested positive were more likely to have regular partners $\left(X^{2}=2 \cdot 75, p=0.28\right)$, and more likely to have disclosed their homosexuality to others $(84 \%)$ than those testing negative $(76 \%)$ (KruskalWallis $\mathrm{H}=0.026, \mathrm{p}=0.87$ ). There is no difference between the positives and negatives in terms of educational qualifications or social class.

The groups are, however, distinguished by their sexual practices. It is important at this point to make the distinction between a sexual partner and a penetrative sexual partner (or psp), that is a partner with whom anal intercourse (either insertive or receptive or both) or, where appropriate, vaginal intercourse occurs.

The numbers of partners and psps are higher for the positives than for the negatives over a number of time periods: the month preceding interview, the previous year, the previous five years, and whole life (see table 5). It should be noted that the distributions are highly skewed and that the median provides a more accurate measure of the central tendency than does the mean. These differences are not significant except in the case of psps over the whole life $(\mathrm{F}=12.18 ; \mathrm{df}=1,181 ; \mathrm{p}<0.01)$. The ratio of psps to partners over time appears, generally, to be decreasing.

Men in the positive group were more likely to report having had syphilis at least once in the past than negatives $\left(37 \%, 12 \%, \mathrm{X}^{2}=6.58, \mathrm{p}=0.01\right)$. Furthermore, among those with a history of syphilis, positives were more likely to have had more episodes $(\mu(+\mathrm{ve})=0.4, \mu(-\mathrm{ve})=0 \cdot 1, \mathrm{~F}=6.44, \mathrm{df}=1$, $148, \mathrm{p}=0.01)$.

Herpes was also more frequently reported by positives $\left(26 \%, 9 \%, \mathrm{X}^{2}=3.88, \mathrm{p}<0.05\right)$, although it should be remembered that herpes is an opportunistic infection common among people with HIV. No 
other sexually transmitted diseases showed any significant differences by HIV-1 status.

\section{Discussion}

If not theoretically impossible, it is, in practice, extremely difficult to collect a random or representative sample of homosexually active men. ${ }^{1}$ In the UK, studies of HIV seroprevalence on this epidemiologically important group have been based on men who attend STD clinics. ${ }^{2-4}$ It is recognised that this group is not representative of the whole population of homosexually active men. ${ }^{5}$ One of the major aims of Project SIGMA was to gather data from a non-clinic cohort and in this, we have been successful. Only $40 \%$ of the men interviewed were regular clinic attenders, although the ratio of clinic attenders to non-attenders in the population is, according to Hillier's estimates, ${ }^{3}$ nearer $1: 10$.

The two cohorts, from London and South Wales, are broadly similar in their demographic outlines and similar, in addition to the samples gained by the project in other sites; ${ }^{6}$ to the sample obtained by McManus and McEvoy ${ }^{7}$ in their postal survey of homosexual behaviour and to that arising from our requests for volunteers to keep sexual diaries ${ }^{8}$ as well as to similar studies in the Netherlands ${ }^{9}$ and Australia. $^{10}$ This congruence over types of study and means of sampling suggests that this is a sample from a well-defined group: that usually referred to as the gay community.

The diversity of that community is demonstrated in our findings. It covers a wide age range. The relative preponderance of men in their twenties and thirties in this group reflects the changes that occurred in the late 1960s and early 1970s when homosexuality was decriminalised and "gay liberation"sought to replace guilt and covertness with pride and openness. But the gay community does not encompass all men who have sex with men. There are clearly men, some married, who prefer not to avow a gay identity but who will nevertheless have sex with men. The Project aimed to contact some of these, and to the extent that $22 \%$ of the cohort kept their identity secret from more than half their families, friends and acquaintances, we may be said to have succeeded. However, it remains likely that many men who have sex will not be represented in this study.

In the London cohort, 19/206 (9.2\%) men tested positive for HIV antibody and in South Wales, 5/147 $(3.4 \%)$. The disparity in the rates is consistent with the conclusions from clinic studies that London forms the epicentre of the HIV epidemic in gay men. The relationship of this figure to the "true" rate of seropositivity is more problematic. Such an estimate is strictly speaking impossible, since the denominator of the equation, the number of homosexually active men in the UK is unknown, nor will estimates of that proportion be possible until a national study of sexual behaviour is undertaken.

Our finding that the rate of antibody positivity is higher in clinic attenders than in those who do not attend is intuitively valid. One would expect men attending STD clinics to be, on the whole, more sexually active than those not attending and, to that extent more likely to come into contact with the $\mathrm{HI}$ virus. Indeed, since the advent of HIV and the consequent uptake of safer sexual practices among gay men, that group attending STD clinics is probably less representative of gay men as a whole than previously. Using our rates in attenders and nonattenders and Hillier's ${ }^{3}$ estimates of 16000 gay men attending STD clinics in London in 1986, and a gay male population of 150000 , we arrive at a figure of about 7500 gay men in Greater London who are seropositive.

It has been suggested ${ }^{11} 12$ that the seropositivity rate among gay men who are voluntarily tested is higher than that obtained on an anonymous test. Figures from a London clinic put this ratio at about $2: 1$. It is clear that the group of men coming to interview with Project SIGMA is different from that attending STD clinics, and those volunteering a blood sample are different from those who would volunteer for testing in a hospital or clinic. It must remain uncertain whether this disparity in rates obtains for our sample, although all the indications are that there are no significant differences (except age) between those volunteering a blood sample and those not doing so. It is also worthy of note that only $42 \%$ of respondents had previously received a HIV test result.

Comparison of the sero-positives and the seronegatives in London reveal that there are no significant demographic differences, although those aged under 21 years have a relatively high rate (about $15 \%)$. This is an important group of men because homosexual sex is illegal under this age. Other data suggest that the mean age for first homosexual experience in this group is about 14 years. Since it is illegal, it is much more difficult for these young men to attend gay groups, feel confident about their sexuality and they do not have easy access to health education material appearing in the gay press, pubs or clubs.

It may appear paradoxical that those with regular partners are more likely to test positive. But it is consistent with findings for our cohort and from other work, ${ }^{13}$ that most unsafe sex occurs within regular relationships. It is also important to note that current HIV antibody positivity may be the result of sexual activity some years ago, especially given that although the mean length of primary partnerships in the cohort is 2.7 years, that is within the dormancy period of HIV.

These findings should sound a warning that age, 
current sexual behaviour, relationship status or reported numbers of partners are not reliable predictors of the likelihood being HIV antibody positive. Clinicians who use these factors to judge the probability of positivity or insurance companies who make decisions about cover on these bases are misguided.

By contrast, it is entirely consistent with current knowledge about the transmission of HIV to find that positives had higher numbers of male penetrative sexual partners (that is, partners with whom anal intercourse had occurred) in their lifetimes than had negatives. Indeed, positives report higher numbers of both partners and psps in all time periods.

The notion of a penetrative sexual partner is, we contend, a crucial one for understanding the spread of HIV through homosexual behaviour and behavioural change amongst homosexually active men. ${ }^{4}$ It seems to be the case that much behaviour change in response to HIV consists of reducing ones psp/ partner ratio. Epidemiological models use three parameters to estimate the future spread of HIV: (1) rate of partner change, (2) infectivity, and (3) length of infectivity. It is assumed that infectivity is fixed for particular modes of relationship (homosexual or heterosexual, for example). ${ }^{14}$ Changes in the psp/ partner ratio, however, change that infectivity parameter and this is not allowed for in current models.

Those testing positive were also more likely to report a previous episode of syphilis than the negative group and they were likely to have had more episodes of syphilis. This reflects their higher rates of anal intercourse. The group with a history of syphilis had a mean of 560 psps in their lives and those without a history $96(\mathrm{~F}=11.51$, df $=1,308$, $\mathrm{p}=0.0008$ ).

This study clearly lends further evidence to support the contention that homosexually active men are having less anal intercourse. Clinic studies came to this conclusion by monitoring the rate of rectal gonorrhoea. Nowadays, men may use condoms during anal intercourse and so may not acquire infections such as gonorrhoea so readily. However, the use of condoms reduces but does not eliminate the possibility of transmitting HIV or, indeed, any sexually transmitted disease.

We have clearly demonstrated that the ratio of psps to partners has decreased since the advent of HIV and AIDS which indicates the efficacy of safer sex education targeted at gay men, by gay men. However, monitoring the prevalence of anal intercourse should be an important ongoing priority. We need to know that gay men are having fewer psps, that is having anal intercourse with fewer partners and if this trend changes, we need to know why. It is too late to spread the message after rates of rectal gonorrhoea have begun to rise.

The research described in this paper was funded by the Medical Research Council and the Department of Health.

Address for correspondence: Peter Weatherburn, Project SIGMA, Department of Social Sciences, South Bank Polytechnic, London Road, London SE1 OAA, UK.

1 Davies PM. Some Problems in the Definition and Sampling of Non-Heterosexual Males, Project SIGMA Working Paper No 3, London, Project SIGMA, 1986.

2 Carne CA, Weller IVD, Johnson AM, et al. Prevalence of antibodies to HIV, gonorrhoea rates and changed sexual behaviour in homosexual men in London. Lancet 1987;i: 656-8.

3 Department of Health/Welsh Office. Short-term Prediction of HIV Infection and AIDS in England and Wales: Report of $a$ Working Group, London: HMSO, 1988.

4 Evans BA, McLean KA, Dawson SD, et al. Trends in sexual behaviour and risk factors for HIV infection among homosexual men 1984-7. Br Med J 1989;298:215-8.

5 Hillier HC. Estimation of HIV Prevalence in England and Wales-the Direct Approach: In: DoH/WO: Short Term Prediction of HIV Infection and AIDS in England and Wales, London, HMSO 1988:48-52.

6 Davies PM, Hunt AJ, Macourt M, Weatherburn P. Longitudinal Study of the Sexual Behaviour of Homosexual males under the Impact of AIDS. Project SIGMA, London, 1990.

7 McManus TJ, McEvoy M. Some Aspects of Male Homosexual Behaviour in the United Kingdom. Br J Sexual Medicine. 1987 (April): 110-20.

8 Coxon APM. Something Sensational ....: The Sexual Diary as a Tool for Mapping Detailed Sexual Behaviour. Sociological Review 1988;36:147-59.

9 van Griensven GJP, de Vroome EMM, Goudsmit J, Coutinho RA. Changes in sexual behaviour and the fall in incidence of HIV infection among homosexual men. Br Med $J$ 1989; 298:218-21.

10 Connell RW, Crawford J, Kippax S, et al. Social Aspects of the Prevention of AIDS: Method and Sample SAPA, Macquarie University, NSW 1988.

11 Hull HF, Bettinger CJ, Gallaher MM, et al. Comparison of HIV-Antibody Prevalence in Patients Consenting to and Declining HIV-Antibody Testing in an STD Clinic. JAMA 1988;260:935-8.

12 Welch J, Palmer S, Banatvala JE, et al. Willingness of homosexual and bisexual men in London to be screened for HIV. $\mathrm{Br}$ Med J 1986;293:924.

13 Gold R, Skinner M, Grant P, Plummer D. Situational Factors Associated with and Rationalisations Employed to Justify Unprotected Intercourse in Gay Men. Paper presented at the Fifth International Conference on AIDS, Montreal, 1989.

14 Anderson R, May R. Plotting the spread of AIDS. New Scientist 1987; 26 March 54-9.

Accepted 3 September 1990 